DOI: $10.17242 / M V v K \_30.10$

\title{
ADATOK A DÉL-BALATONI HALASTAVAK ÉS BERKEK VÍZIMADÁR FAJAINAK SZAPORULATÁRÓL
}

\author{
WATERBIRD SPECIES REPRODUCTION DATA OF THE FISHPONDS AND \\ MARSHES AT SOUTH BALATON
}

\author{
Kovács Gyula \\ Soproni Egyetem, Vadgazdálkodási és Gerinces Állattani Intézet \\ University of Sopron, Institute of Wildlife Management and Vertebrate Zoology \\ H-9400 Sopron, Bajcsy-Zs. u. 4., Hungary, e-mail: delbalaton@gmail.com \\ MME Dél-Balatoni Helyi Csoport \\ BirdLife Hungary South-Balaton Local Group \\ H-8638 Balatonlelle, Irmapuszta, Hungary
}

\section{BEVEZETÉS}

Fészkelő vízimadaraink állományáról és szaporulatáról sajnos kevés hazai szakirodalom áll rendelkezésre, ezen adatok is jellemzően becslésekre alapulnak. A következökben hét vízimadárfajról közlöm a dél-balatoni felmérési eredményeimet.

\section{ANYAG ÉS MÓDSZER}

A terepi felméréseket a dél-balatoni halastavakon és berkekben (KovÁcs, 2009; 2011) végeztem 2007-2014 között. A költési szezonból két faj szaporulatára vonatkozóan átfogó adatsorral csak 2007-ből, illetve az egyiknél még 2009-ből rendelkeztem, így elemzés erre az időszakra készült, azonban hasznosnak láttam a többi adatot is közre adni. A megfigyelések során egyes fajoknál (pl. üstökös réce, szárcsa) a családok nem voltak jól elkülöníthetök, mivel jellemzően nagy számban aggregálódtak, emiatt ezekről kevesebb adat gyült össze.

A túlélési valószínüség meghatározása MAYFIELD (1975) módszere alapján történt, ugyanakkor mivel az egyedi azonosításra nem volt lehetőség, ezért az átlagokkal számoltam. Az átlagos fiókaszám összehasonlítására Kruskal-Wallis és Mann-Whitney próbát, az arányok összehasonlítására khí-négyzet próbát alkalmaztam. Az értékeléshez PAST v.2.17 (HAMMER et al., 2001) programot használtam.

\section{EREDMÉNYEK ÉS ÉRTÉKELÉSÜK}

A nyári lúd (Anser anser) dél-balatoni fészkelőállománya jelentős és évtizedek óta stabil. Gyakorlatilag valamennyi vizes élőhelyen előfordul a Balaton déli partja mentén. A családok száma és az átlagos fiókaszám a Fonyódi-halastavakon volt a legmagasabb (4,8 fióka/család), ami vélhetően annak köszönhető, hogy ez a terület viszonylag zárt és az állandó emberi jelenlét tompíthatja a predációs nyomást. Ugyanakkor az összesen felmért 362 család átlagos fiókaszáma (1-3. táblázat) a vizsgált három területen nem tért el szignifikánsan (KruskalWallis próba $\chi^{2}=1,27 ; p=0,52$ ). Az Irmapusztai-halastavak esetében 2007-ben és 2009-ben egyaránt 0,03 fióka/család volt az átlagos napi veszteség, ami havonta 0,8 fióka/család csökkenést jelentet, bár a tendencia egyik évben sem volt szignifikáns (1. ábra). Az átlagos fiókaszámban nem volt lényeges eltérés a két évben (Mann-Whitney próba $z=1,59 ; p=0,11$ ). A napi túlélési valószínűség a MAYFIELD-módszer alapján 2007-ben 97,5\%, 2009-ben 98,1\% 
volt. Tíz hetes fiókanevelési időszakkal számolva az első évben 17\%, két évvel később 27\% volt valószínűsége, hogy egy fióka megéri az időszak végét. Ugyanakkor a napi fiókaszám-

1. táblázat: Nyári lúd családok a fiókaszámok szerint a Balatonszárszói-halastavon és berekben

Table 1: Greylag goose families according to the number of goslings on the fishpond and marsh at Balatonszárszó

\begin{tabular}{|c|c|c|c|c|c|c|c|c|}
\hline $\begin{array}{l}\text { Fiókák száma } \\
\text { No. of goslings }\end{array}$ & 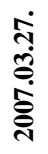 & $\begin{array}{l}\dot{0} \\
\dot{\overrightarrow{0}} \\
\stackrel{\tilde{\sigma}}{0}\end{array}$ & 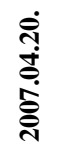 & $\begin{array}{l}\dot{S} \\
\stackrel{0}{0} \\
\stackrel{\tilde{\delta}}{0}\end{array}$ & 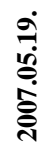 & $\begin{array}{l}\stackrel{\leftrightarrow}{\circ} \\
\stackrel{+}{0} \\
\stackrel{0}{0}\end{array}$ & 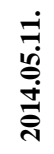 & $\begin{array}{l}\text { Családok össz. } \\
\text { Families total }\end{array}$ \\
\hline 1 & & & & & & & 2 & 2 \\
\hline 2 & & 3 & 3 & 2 & & 1 & 2 & 11 \\
\hline 3 & & & & 1 & 2 & 2 & 1 & 6 \\
\hline 4 & & 1 & 1 & 2 & 1 & 7 & & 12 \\
\hline 5 & & 3 & & 3 & 1 & 1 & 2 & 10 \\
\hline 6 & 2 & & & 2 & & 1 & 1 & 6 \\
\hline 12 & & & 1 & & & & & 1 \\
\hline 14 & & 1 & & & & & & 1 \\
\hline $\begin{array}{c}\text { Családok száma } \\
\text { No. of families }\end{array}$ & 2 & 8 & 5 & 10 & 4 & 12 & 8 & 49 \\
\hline Átlag/Mean & & 4,9 & 4,4 & 4,2 & 3,8 & 3,9 & 3,1 & 4,1 \\
\hline SE & & 1,4 & 1,9 & 0,5 & 0,5 & 0,3 & 0,7 & 0,3 \\
\hline
\end{tabular}

2. táblázat: Nyári lúd családok a fiókaszámok szerint a Fonyódi-halastavakon

Table 2: Greylag goose families according to the number of goslings on the fishponds at Fonyód

\begin{tabular}{|c|c|c|c|c|c|c|}
\hline $\begin{array}{l}\text { Fiókák száma } \\
\text { No. of goslings }\end{array}$ & 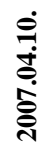 & 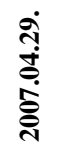 & 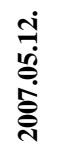 & $\begin{array}{l}\dot{0} \\
\stackrel{0}{0} \\
\stackrel{0}{0} \\
\stackrel{0}{0}\end{array}$ & 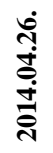 & $\begin{array}{c}\text { Családok össz. } \\
\text { Families total }\end{array}$ \\
\hline 1 & & 2 & 1 & 2 & 2 & 7 \\
\hline 2 & 2 & 4 & 4 & 6 & 2 & 18 \\
\hline 3 & 2 & 7 & 3 & 7 & 3 & 22 \\
\hline 4 & 2 & 12 & 13 & 2 & 4 & 33 \\
\hline 5 & 3 & 4 & 2 & 2 & 2 & 13 \\
\hline 6 & & 5 & 3 & 1 & 1 & 10 \\
\hline 7 & & 2 & 2 & & 2 & 6 \\
\hline 8 & 2 & 1 & 3 & 1 & & 7 \\
\hline 9 & 2 & 2 & & & & 4 \\
\hline 10 & & 1 & & & & 1 \\
\hline 11 & & 1 & & & & 1 \\
\hline 12 & 1 & 1 & & 1 & & 3 \\
\hline 13 & & 1 & & & & 1 \\
\hline 14 & & 1 & & & & 1 \\
\hline 15 & 1 & 1 & & & & 2 \\
\hline 16 & & 1 & & & & 1 \\
\hline $\begin{array}{c}\text { Családok száma } \\
\text { No. of families }\end{array}$ & 15 & 46 & 31 & 22 & 16 & 130 \\
\hline Átlag/Mean & 6,3 & 5,7 & 4,4 & 3,6 & 3,8 & 4,8 \\
\hline SE & 1,0 & 0,5 & 0,3 & 0,5 & 0,5 & 0,3 \\
\hline
\end{tabular}

3. táblázat: Nyári lúd családok a fiókaszámok szerint az Irmapusztai-halastavakon

Table 3: Greylag goose families according to the number of goslings on the fishponds at Irmapuszta

\begin{tabular}{|c|c|c|c|c|c|c|c|c|c|c|c|c|c|c|c|c|c|c|}
\hline $\begin{array}{l}\text { Fiókák száma } \\
\text { No. of goslings }\end{array}$ & 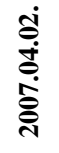 & 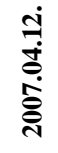 & 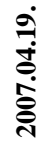 & 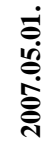 & 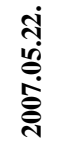 & $\begin{array}{l}\dot{\Omega} \\
\hat{\theta} \\
\stackrel{0}{0} \\
\hat{\sigma}\end{array}$ & 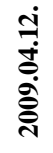 & 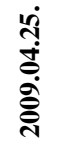 & 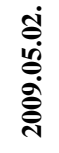 & 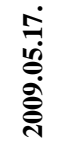 & 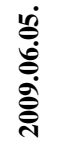 & 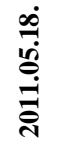 & $\begin{array}{l}\dot{\sigma} \\
\dot{0} \\
\dot{\Xi} \\
\dot{\Xi}\end{array}$ & 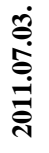 & $\begin{array}{l}\dot{8} \\
\dot{\Xi} \\
\dot{\Xi} \\
\dot{\Xi}\end{array}$ & 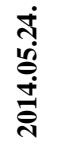 & 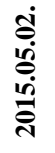 & $\begin{array}{c}\text { Családok össz. } \\
\text { Families total }\end{array}$ \\
\hline 1 & 2 & & 1 & 1 & 1 & & 1 & & 1 & 2 & & 5 & & 1 & & 1 & 1 & 17 \\
\hline 2 & & 1 & 1 & 2 & 1 & 2 & 1 & & 3 & 1 & 1 & 3 & 1 & & & & 3 & 20 \\
\hline 3 & 2 & 5 & 5 & 1 & 1 & & & 4 & 7 & & 1 & 3 & & & & 3 & 5 & 37 \\
\hline 4 & 4 & 5 & 3 & & & & & 4 & 5 & 1 & 1 & & & & 2 & 2 & 3 & 30 \\
\hline 5 & 8 & 5 & 3 & 2 & & & & & 3 & 1 & & & & & 6 & 2 & 1 & 31 \\
\hline 6 & 1 & 2 & 3 & 1 & & & 1 & 1 & 3 & & & 1 & & & 2 & & 4 & 19 \\
\hline 7 & 2 & 1 & 2 & 1 & & & 1 & 2 & 2 & 1 & & & & & & & 1 & 13 \\
\hline 8 & 1 & 1 & & 1 & & & & 1 & 2 & & & & & & & & & 6 \\
\hline 9 & & 1 & 1 & & 1 & & & & & & & & & & & & & 3 \\
\hline 10 & & 1 & & & & & & & 1 & & & & & & & & & 2 \\
\hline 11 & & 1 & & & & & & & & & & & & & & & & 1 \\
\hline 12 & & & & 1 & & & & & & & & & & & & & & 1 \\
\hline 13 & 1 & 1 & 1 & & & & & & & & & & & & & & & 3 \\
\hline $\begin{array}{l}\text { Családok száma } \\
\text { No. of families }\end{array}$ & 21 & 24 & 20 & 10 & 4 & 2 & 4 & 12 & 27 & 6 & 3 & 12 & 1 & 1 & 10 & 8 & 18 & 183 \\
\hline Átlag/Mean & 5,0 & 5,5 & 5,0 & 5,1 & 3,8 & & 4,0 & 4,7 & 4,5 & 3,3 & 3,0 & 2,2 & & & 5,0 & 3,5 & 3,9 & 4,4 \\
\hline SE & 0,5 & 0,6 & 0,6 & 1,1 & 1,8 & & 1,5 & 0,5 & 0,4 & 1,0 & 0,6 & 0,4 & & & 0,2 & 0,5 & 0,4 & 0,2 \\
\hline
\end{tabular}




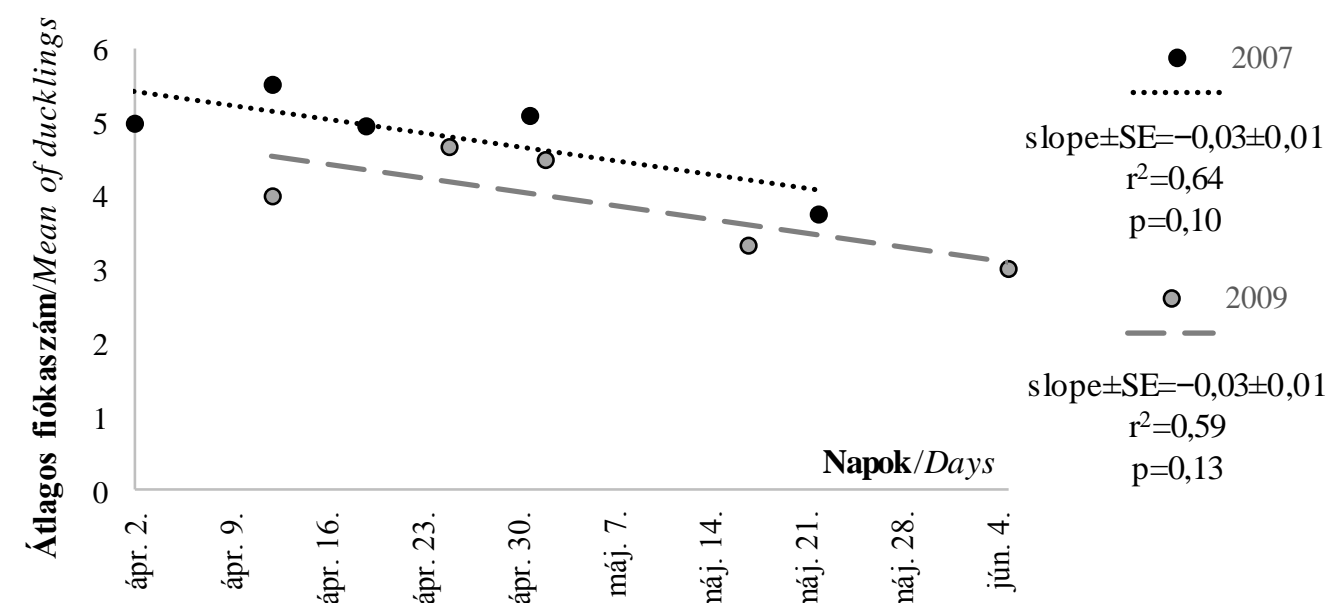

1. ábra: A nyári lúd családok átlagos fiókaszámának változása az Irmapusztaihalastavakon 2007-ben és 2009-ben

Figure 1: The change of the average Greylag Goose goslings on the fishponds at Irmapuszta in 2007 and 2009

csökkenésből kalkulálva a fiókák $62,8 \%$, illetve 52,3\%-a érhette meg a röpképes kort. DélSvédországban 1988-1994 között az arány 64-67\% volt (NILSSON et al., 1997).

A barátréce (Aythya ferina) esetében az összes adat átlaga 4,2 fióka/család volt június és július hónapokban. A 2007-ben az Irmapusztai-halastavakon végzett felmérés alapján a napi fiókaszámcsökkenés ennél a fajnál magasabb volt, ugyanakkor a fogyás trendje itt sem volt szignifikáns (slope $\pm \mathrm{SE}=-0,06 \pm 0,03 ; \mathrm{r}^{2}=0,69 ; \mathrm{p}=0,17$ ). Egy hét alatt átlagosan 0,4 fióka/család, egy hónap alatt 1,8 fióka/család volt a veszteség. A vizsgálat első (június 09.) és utolsó napja (július 13.) közötti bő egy hónap átlagának eltérése már számottevő volt (MannWhitney próba $z=3,12 ; p=0,002)$, még akkor is, ha a 12 fiókás kiugró értéket nem vesszük figyelembe. A fiókák napi túlélési rátája 91,6\% volt, 7-8 hetes fiókakort figyelembe véve az utódok túlélési esélye rendkívül alacsony, mindössze 1\% körüli. A napi csökkenés lineáris trendje alapján ugyanakkor a fiókák 42\%-a is megérhette a fiókakor végét.

4. táblázat: Barátréce családok a fiókaszámok szerint a dél-balatoni halastavakon Table 4: Pochard families according to the number of ducklings on the fishponds at South Balaton

\begin{tabular}{|c|c|c|c|c|c|c|c|c|}
\hline \multirow{2}{*}{$\begin{array}{l}\text { Fiókák száma } \\
\text { No. of ducklings }\end{array}$} & \multicolumn{5}{|c|}{$\begin{array}{l}\text { Irmapusztai-halastavak } \\
\text { Fishponds at Irmapuszta }\end{array}$} & \multicolumn{2}{|c|}{$\begin{array}{l}\text { Fonyódi-halastavak } \\
\text { Fishponds at Fonyód }\end{array}$} & \multirow{2}{*}{$\begin{array}{l}\text { Családok össz. } \\
\text { Families total }\end{array}$} \\
\hline & 2007.06.09. & 2007.06.15. & 2007.07.03. & 2007.07.13. & 2010.07 .04$. & 2007.07.02. & 2007.07.11. & \\
\hline 1 & & 1 & 1 & & & & & 2 \\
\hline 2 & & 3 & 2 & 6 & & 1 & & 12 \\
\hline 3 & 3 & 2 & 2 & 3 & & & & 10 \\
\hline 4 & 1 & 4 & 2 & & 1 & & & 8 \\
\hline 5 & 1 & 1 & 2 & & & & & 4 \\
\hline 6 & 4 & 1 & & 1 & & & 4 & 10 \\
\hline 7 & 1 & & 2 & & & & & 3 \\
\hline 8 & & 2 & 1 & & & & & 3 \\
\hline 12 & 1 & & & & & & & 1 \\
\hline $\begin{array}{l}\text { Családok száma } \\
\text { No. of families }\end{array}$ & 11 & 14 & 12 & 10 & 1 & 1 & 4 & 53 \\
\hline Átlag/Mean & 5,5 & 4,0 & 4,3 & 2,7 & & & & 4,2 \\
\hline SE & 0,8 & 0,6 & 0,6 & 0,4 & & & & 0,3 \\
\hline
\end{tabular}

Az üstökös réce (Netta rufina) családok átlagos fiókaszáma 4,9 $\pm 0,4$ (átlag \pm SE) (5. táblázat), a búbos vöcsök esetében (Podiceps cristatus) 2,2 $\pm 0,5$ (átlag \pm SE) (6. táblázat) volt a dél-balatoni vizesélöhelyeken. 


\section{5. táblázat: Üstökös réce családok a fiókaszámok szerint a dél-balatoni halastavakon és berkekben}

Table 5: Red-crested Pochard families according to thenumber of ducklings on the fishponds and marshes at South Balaton

\begin{tabular}{|c|c|c|c|c|c|c|c|}
\hline \multirow{2}{*}{$\begin{array}{l}\text { Fiókák száma } \\
\text { No. of ducklings }\end{array}$} & \multirow{2}{*}{$\begin{array}{c}\text { Balatonszárszói-berek } \\
\text { Marsh at Balatonszárszó } \\
\mathbf{2 0 0 8 . 0 6 . 1 5} \\
\end{array}$} & \multicolumn{5}{|c|}{$\begin{array}{l}\text { Irmapusztai-halastavak } \\
\text { Fishponds at Irmapuszta }\end{array}$} & \multirow{2}{*}{$\begin{array}{l}\text { Családok össz. } \\
\text { Families total }\end{array}$} \\
\hline & & 2007.05.22. 2007.06 & 06.09. 2007.06 & 0.07 & 1.0 & 1.07.03. & \\
\hline 3 & \multirow{4}{*}{1} & \multirow{3}{*}{1} & 1 & & & & 1 \\
\hline 4 & & & 1 & & & \multirow{3}{*}{1} & 3 \\
\hline 5 & & & & & & & 1 \\
\hline 6 & & 1 & 1 & 1 & 1 & & 4 \\
\hline $\begin{array}{c}\text { Családok száma } \\
\text { No. of families }\end{array}$ & 1 & 1 & 3 & 1 & 1 & 1 & 9 \\
\hline
\end{tabular}

6. táblázat: Búbos vöcsök családok a fiókaszámok szerint a dél-balatoni halastavakon és berkekben

Table 6: Great Crested Grebe families according to the number of ducklings on the fishponds and marshes at South Balaton

\begin{tabular}{|c|c|c|c|c|c|c|}
\hline \multirow{2}{*}{$\begin{array}{l}\text { Fiókák száma } \\
\text { No. of nestlings }\end{array}$} & \multicolumn{2}{|c|}{$\begin{array}{l}\text { Balatonszárszói-berek } \\
\text { Marsh at Balatonszárszó }\end{array}$} & \multicolumn{3}{|c|}{$\begin{array}{l}\text { Irmapusztai-halastavak } \\
\text { Fishponds at Irmapuszta }\end{array}$} & \multirow{2}{*}{$\begin{array}{l}\text { Családok össz. } \\
\text { Families total }\end{array}$} \\
\hline & 2007.05 .25 & 2008.06.15. & 2007.07 .13 & 2010.07 .04 & 2011.07.03. & \\
\hline 1 & & 1 & 4 & & & 5 \\
\hline 2 & & & 3 & 2 & 1 & 6 \\
\hline 4 & & & & & 1 & 1 \\
\hline 8 & 1 & & & & & 1 \\
\hline $\begin{array}{l}\text { Családok száma } \\
\text { No. of families }\end{array}$ & 1 & 1 & 7 & 2 & 2 & 13 \\
\hline
\end{tabular}

További három faj adatai. Cigányréce (Aythya nyroca) 2007.07.02., Fonyódihalastavak $2 \times 4$ fiókás és $2 \times 7$ fiókás család. Kis vöcsök (Tachybaptus ruficollis) 2007.07.02., Ordacsehi-berek $1 \times 2$ fiókás és $1 \times 3$ fiókás család. Szárcsa (Fulica atra) Irmapusztaihalastavak, 2011.05.18. $1 \times 2$ fiókás és $1 \times 3$ fiókás; 2015.05.02. 1×2 fiókás család.

\section{IRODALOMJEGYZÉK}

Hammer, Ø., Harper, D. A. T. \& RyAn, P. D. (2001): PAST: Paleontological Statistics Software Package for Education and Data Analysis. Palaeontologia Electronica 4 (1): $9 \mathrm{p}$.

KovÁCS GY. (2009): Vizes élőhelyek (halastavak, berkek) funkcionális szerepe a Balaton déli partján. In: LAKATOS F. \& KUI B. (szerk.): Nyugat-magyarországi Egyetem Erdömérnöki Kar, Kari Tudományos Konferencia. Sopron, 2009. október 12. Konferencia kötet. pp. 224-225.

KovÁcs Gy. (2011): The ecological function of the wetland habitat fragments (fishponds, marshes) at Lake Balaton. In: Puigcerver, M., TeiJeiro, J. D. R. \& Buner, F. (eds.): Abstracts of XXXth IUGB Congress and Perdix XIII. Barcelona, Spain, 5th-9th September 2011. p. 220.

MAYFIELD, H. (1975): Suggestions for calculating nest success. Wilson Bulletin 87: 456-466.

Nilsson, L., Persson, H. \& Voslamber, B. (1997): Factors Affecting Survival of Young Greylag Geese Anser anser and Their Recruitment into the Breeding Population. Wildfowl 48: 72-87. 


\title{
WATERBIRD SPECIES REPRODUCTION DATA OF THE FISHPONDS AND MARSHES AT SOUTH BALATON
}

\author{
Kovács, Gy.
}

\section{Summary}

Breeding waterbird surveys have been carried out on the fishpond and marshes at South Balaton between 2007 and 2014. In this paper the reproduction data of seven species were presented. Detailed data of Greylag Goose (Anser anser) (Table 1-3) and Pochard (Aythya ferina) (Table 4) are given, while only few data of Red-crested Pochard (Netta rufina) (Table 5), Great Crested Grebe (Podiceps cristatus) (Table 6), Ferruginous Duck (Aythya nyroca), Little Grebe (Tachybaptus ruficollis) and Coot (Fulica atra) are included. 
